\title{
Comparison of Early versus Interval Tonsillectomy in Cases of Peritonsillar Abscess
}

Muhammad Ahmed Khan ${ }^{1}$, Attique Ahmed², Muhammad Khan ${ }^{3}$

\section{ABSTRACT}

Objective: To compare early versus interval tonsillectomy in cases of peritonsillar abscess.

Study Design: Comparative study.

Place and Duration of Study: The study was carried out at ENT Department of Combined Military Hospital, Mardan from January 2017 to January 2018.

Materials and Methods: A total 50 patients were selected from ENT outpatient department. All the cases were randomly divided into two groups of 25 each. Group A underwent early tonsillectomy after initial incision and drainage, Group B underwent interval tonsillectomy after 6 weeks. Both the groups were compared in terms of perioperative blood loss, operation time, ease of dissection and postoperative complications including pain and hemorrhage. Tonsillectomy was done with bipolar cautery in all the cases.

Results: The mean age was $30.22 \pm 8.25$. Out of 50 patients, 42 (84\%) were males and 8 (16\%) were females. The mean operative time of surgery in group A (early tonsillectomy) was $45.04 \pm 5.78$ minutes compared to $32.72+4.37$ minutes for group B (interval tonsillectomy $(p=0.00)$. Mean post-operative pain in group A was $3.68 \pm 2.12$ compared to group $B$ where mean score was $3.36 \pm 1.93(p=0.579)$. There were 3 cases of mild perioperative blood loss, 19 cases of moderate and 3 of severe perioperative blood loss in group $A$. There were 18 cases of mild perioperative blood loss, 7 cases of moderate and no case of severe perioperative blood loss in group $B(p=0.00)$. Dissection was found to be significantly easier in group B (interval tonsillectomy). There were 7 cases of post-op secondary hemorrhage in group A compared to 3 in group $B(p=0.289)$. All these cases of secondary hemorrhage were managed conservatively.

Conclusion: Interval tonsillectomy is a safer procedure as compared to early tonsillectomy in terms of perioperative blood loss, operative time, dissection with almost similar post-op pain and similar risk of post tonsillectomy hemorrhage.

\section{Key Words: Early Tonsillectomy, Interval Tonsillectomy, Peritonsillar Abscess.}

How to cite this: Khan MA, Ahmed A, Khan M. Comparison of Early versus Interval Tonsillectomy in Cases of Peritonsillar Abscess. Life and Science. 2020; 1(1): 23-27. doi: https://doi.org/10.37185/LnS.1.1.13

\section{Introduction}

Peritonsillar abscess (PTA), also known as quinsy, is simply defined as localized bacterial infection of the head and neck that occurs usually as a complication of tonsillitis, leading to accumulation of pus between the capsule of palatine tonsil and muscles of

\footnotetext{
${ }^{1}$ Department of ENT

Combined Military Hospital, Mardan

${ }^{2}$ Department of ENT

Combined Military Hospital, Bahawalpur

${ }^{3}$ Department of ENT

Combined Military Hospital, Lahore

Correspondence:

Dr. Muhammad Ahmed Khan

Department of ENT

Combined Military Hospital, Mardan

E-mail:akawan79@gmail.com

Funding Source: NIL; Conflict of Interest: NIL

Received: Aug 29, 2018; Revised: Nov 04, 2019

Accepted: Dec 04, 2019
}

pharynx..$^{1-4}$ As this area consists of loose connective tissue, such infection leads to the formation of pus or purulent material in this region. Due to extensive spread of inflammation it may extend to soft palate, walls of pharynx and to the base of the tongue..$^{2-5}$ The causative bacteria of PTA include group A streptococcus, anaerobic and gram-negative rods. It is seen that $90 \%$ of cultures contain anaerobic bacteria and that of 25 to $40 \%$ contain group A streptococci. ${ }^{6}$ The etiology is still unknown.

The symptoms of peritonsillar abscess are somehow similar to streptococcal pharyngitis and tonsillitis. Symptoms include difficulty in swallowing saliva, sore throat usually worse on one side, difficulty in opening mouth, fever, dysphasia and swollen gland in the throat and ear pain on the side of sore throat. ${ }^{7}$ Difficulty in swallowing is due to inflammatory edema. ${ }^{8}$ Although peritonsillar abscess can occur in 
any age but the peak age incidence is $20-40$ years. ${ }^{9,10}$ The diagnosis of PTA requires clinical history and through physical examination, transoral ultrasound and CT scan. If this condition is not adequately treated or remains untreated it can become potentially life threatening, leading to severe and serious conditions like parapharyngeal abscess, airway obstruction, mediastinitis, sepsis and erosion of the internal carotid artery. ${ }^{11}$ Airway obstruction may occur due to severe inflammation resulting in infection surrounding the area of head and neck region. To prevent airway obstruction and perforation of abscess into parapharyngeal spaces, proper and adequate diagnosis and treatment must be done. .,12 $^{-12}$

The treatment consists of antimicrobial therapy and drainage of abscess followed by tonsillectomy. Peritonsillar abscess can be drained through incision drainage or needle aspiration. Tonsillectomy is one of the most acceptable surgeries performed world wide. To prevent recurrence and complications of peritonsillar abscess, tonsillectomy is best option to be performed. ${ }^{12}$ Immediate tonsillectomy, also known as abscess tonsillectomy or hot tonsillectomy, is a procedure done on emergency basis without any needle aspiration, incision or drainage. Early tonsillectomy is carried out after a few days, within a week $^{13}$ if the procedure is performed after needle aspiration, incision or drainage at the interval of 4 to 6 weeks it is termed as delayed or interval tonsillectomy. ${ }^{14}$

The purpose of our study is to compare early tonsillectomy and interval tonsillectomy and compare pre and post-operative complications of early versus interval tonsillectomy.

\section{Materials and Methods}

The study was parallel group, comparative, triple blinded study conducted at ENT Department of Combined Military Hospital, Mardan. The study duration was one year from January 2017 to January, 2018. The study intended to treat peritonsillar abscess patients comparing the two management approaches. Management for peritonsillar abscess were assessed and compared in two groups; one getting early tonsillectomy and the other group of patients had to undergo interval tonsillectomy. The study was approved by the Research Ethics Board. Informed consent was taken from patients after explaining the study to them.

The Research Coordinator at the ENT OPD enrolled and assigned eligible patients using randomly generated sequences in opaque sealed envelopes. The details of the series were unknown to any of the investigators or the coordinator. A total of 50 (25 in each arm) patients were randomly assigned to one of the two parallel groups after taking informed consent, initially in 1:1 ratio, to receive either one of the two management approaches for peritonsillar abscess. Study investigators, research coordinators, statistician and the patients were blinded to this allocation. These patients, selected from the ENT outpatient department, were seen by otorhinolaryngologists in the outpatient department and were diagnosed clinically. In peritonsillar abscess, affected tonsil looks swollen, edematous and erythematous. Uvula is deviated to opposite side, there is trismus and severe odynophagia along with hot potato voice.

\section{Inclusion Criteria}

1. Clinically diagnosed cases of peritonsillar abscess who had not undergone any procedure for abscess drainage.

\section{Exclusion Criteria}

1. Patients who had chronic liver diseases, chronic renal diseases or immunocompromised condition.

2. Patients who had any bleeding or clotting disorder.

In all cases of quinsy, immediate intravenous antibiotic Augmentin was started followed by incision and drainage under local anesthesia by spraying $10 \%$ lignocaine spray. The group A patients underwent early tonsillectomy on the $3^{\text {rd }} / 4^{\text {th }}$ day and group $B$ patients underwent interval tonsillectomy after 6 weeks. Both the groups were compared for perioperative blood loss, operation time, ease of dissection and postoperative complications including pain and hemorrhage. Tonsillectomy was done with bipolar cautery in all the cases. Cautery uses electrical current to heat metal wire that is applied to target tissue in order to burn or coagulate the specific area of tissue. Blood loss during surgery was assessed meticulously. Before starting operation, good amount of ribbon gauze along with cotton was taken, weighed and sterilized. Suction bottle and rubber tube was cleaned and emptied. All 
blood lost during surgery was collected in suction bottle. Once tonsils were removed, they were squeezed into gauze. All the packs and cotton balls were kept in physical balance and weighed. Blood collected in suction bottles was also measured. Blood weighed in gauze and cotton balls was converted into milliliters by dividing weight by specific gravity, which is $1.055 .{ }^{15}$ Perioperative blood loss was categorized into mild, moderate and severe depending on the amount of blood loss. Blood loss of $50 \mathrm{ml}$ or less was considered mild, 50 to $100 \mathrm{ml} \mathrm{blood}$ loss was considered moderate and more than $100 \mathrm{ml}$ blood loss was termed severe. Operation time was calculated in minutes and recorded for all cases. Dissection was categorized into 'Easy Dissection', 'Moderately difficult Dissection', 'Difficult Dissection' and 'Very Difficult Dissection' depending upon the situation during tonsillectomy. Dissection was termed easy when plane of dissecting the tonsil was easily dissectible. It was termed moderately difficult when plane of dissection was more difficult to find while dissecting out the tonsil. Similarly, difficult dissection was labelled in those cases where plane of dissection was even more difficult to find. Dissection was termed very difficult when plane of dissecting the tonsil was almost impossible to find to dissect out the tonsil. Postoperative complications i.e. pain and hemorrhage were also noted. Pain was categorized into mild, moderate and severe. Pain was checked by allotting pain score from 1 to 10 . Pain score from 1 to 3 was considered mild, from 4 to 6 considered moderate and from 7 to 10 was considered severe pain. Pain was assessed on the $1^{\text {st }}$, $2^{\text {nd }}$ and $5^{\text {th }}$ post-op day and an average of these 3 days was taken for each case and recorded.

Primary hemorrhage occurs within first 24 hours after tonsillectomy. ${ }^{16}$ Secondary postoperative hemorrhage occurs usually 5 to 10 days after tonsillectomy. Both the groups were also compared for primary and secondary hemorrhages.

Data was analyzed using Statistical Package for Social Sciences (SPSS) version 20. Frequency and percentage were calculated for qualitative variables while mean and standard deviation (SD) were calculated for quantitative variables. Chi-square was used to compare qualitative variables between the two groups, $p$-value $<0.05$ was considered significant.

\section{Results}

The age range was from 16 to 45 years with mean age $30.22 \pm 8.25$. The number of males were 42 . Both the groups were comparable in terms of age and gender. Mean age of cases in group A was $29.44+7.82$ and in group $B$ was $31 \pm 8.75$ (Table 1 ).

\begin{tabular}{|c|c|c|c|}
\hline Group & $\mathbf{N}$ & Mean Age & Standard Deviation \\
\hline A & 25 & 29.44 & 7.82 \\
\hline B & 25 & 31.00 & 8.75 \\
\hline Total & 50 & 30.22 & 8.29 \\
\hline
\end{tabular}

Mean operative time of surgery in group A (early tonsillectomy) was $45.04 \pm 5.78$ minutes. In comparison, operative time of surgery in group $B$ (interval tonsillectomy) was $32.72 \pm 4.37$ minutes (Table 2). The difference was statistically significant.

\begin{tabular}{cccc}
\hline \multicolumn{3}{l}{ Table 2: Operative Time of Surgery } \\
\hline Group & N & $\begin{array}{c}\text { Mean Operative } \\
\text { Time (Minutes) }\end{array}$ & Standard Deviation \\
A & 25 & 45.04 & 5.78 \\
B & 25 & 32.72 & 4.37 \\
Total & 50 & 38.88 & 8.03 \\
\hline
\end{tabular}

Pain was assessed in all cases of both groups and categorized as mild, moderate and severe along with assigning a certain number from 0 to 10 . Mean postoperative pain in both groups was calculated, in group $A$ it was $3.68 \pm 2.12$ compared to group $B$ where mean score was $3.36 \pm 1.93$. This difference of pain was not significant ( $p=0.579)$ as shown in Table 3 .

\begin{tabular}{cccc}
\hline \multicolumn{4}{l}{ Table 3: Pain Score } \\
$\mathbf{N}$ & Mean pain score & Standard Deviation \\
\hline Group & $\mathbf{N}$ & 2.12 \\
A & 25 & 3.68 & 1.93 \\
B & 25 & 3.36 & 2.02 \\
Total & 50 & 3.52 & \\
\hline
\end{tabular}

There was a significant difference of perioperative blood loss in both groups $(p=0.000)$, as shown in Table 4. There was significantly more blood loss in group $A$ as compared to group $B$. There were 3 cases of mild perioperative blood loss in group $A$ as compared to 18 cases in group $B, 19$ cases of moderate loss in group $A$ versus 7 in group $B$ and 3 cases of severe perioperative blood loss versus none in group B. Similarly, dissection during tonsillectomy was significantly $(p<.001)$ more difficult in group $A$ as compared to group B (Table 4). There was no case of primary postoperative hemorrhage in both 
groups. There were 7 cases of secondary hemorrhage in group $A$ patients as compared to 3 cases in group $B$, but this difference was insignificant $(p=0.0289)$. All these secondary hemorrhage cases were managed conservatively, and none needed electrocoagulation under general anesthesia which is required in extreme or refractory cases.

\begin{tabular}{|c|c|c|c|c|c|}
\hline \multirow[t]{2}{*}{ Comparison } & \multirow[t]{2}{*}{ Categories } & \multicolumn{2}{|c|}{ Groups } & \multirow[t]{2}{*}{ Total } & \multirow[t]{2}{*}{$P$ value } \\
\hline & & A & B & & \\
\hline \multirow{2}{*}{$\begin{array}{l}\text { Perioperative } \\
\text { Blood Loss }\end{array}$} & Mild & 3 & 18 & 21 & \multirow[b]{2}{*}{$p<.001$} \\
\hline & $\begin{array}{l}\text { Moderate } \\
\text { Severe }\end{array}$ & $\begin{array}{c}19 \\
3\end{array}$ & $\begin{array}{l}7 \\
0\end{array}$ & $\begin{array}{c}26 \\
3\end{array}$ & \\
\hline \multirow[t]{2}{*}{$\begin{array}{l}\text { Ease of } \\
\text { dissection }\end{array}$} & $\begin{array}{l}\text { Mild } \\
\text { Moderately } \\
\text { difficult }\end{array}$ & $\begin{array}{l}0 \\
7\end{array}$ & $\begin{array}{c}3 \\
15\end{array}$ & $\begin{array}{c}3 \\
22\end{array}$ & \multirow[t]{2}{*}{$p=0.013$} \\
\hline & $\begin{array}{l}\text { Difficult } \\
\text { Very } \\
\text { difficult }\end{array}$ & $\begin{array}{c}12 \\
6\end{array}$ & $\begin{array}{l}5 \\
2\end{array}$ & $\begin{array}{c}17 \\
8\end{array}$ & \\
\hline Postoperative & Mild & 16 & 16 & 32 & \multirow[t]{2}{*}{$p=0.871$} \\
\hline Pain & $\begin{array}{l}\text { Moderate } \\
\text { Severe }\end{array}$ & $\begin{array}{l}6 \\
3\end{array}$ & $\begin{array}{l}7 \\
2\end{array}$ & $\begin{array}{c}13 \\
5\end{array}$ & \\
\hline Secondary & Yes & 7 & 3 & 10 & $p=0.289$ \\
\hline Hemorrhage & $\begin{array}{l}\text { No } \\
\text { Total }\end{array}$ & $\begin{array}{l}18 \\
25\end{array}$ & $\begin{array}{l}22 \\
25\end{array}$ & $\begin{array}{l}40 \\
50\end{array}$ & \\
\hline
\end{tabular}

\section{Discussion}

Peritonsillar abscess is more common in males than females. ${ }^{9,10}$ Our study showed the same pattern. The age range of our patients was 16 to 45 years with mean $30.22 \pm 8.29$. Other studies ${ }^{9,10}$ also reported similar age groups. Javed $\mathrm{M}$ et al. showed the average age to be $30.9 .^{14}$ Males comprised $63 \%$ of our participants. We used bipolar cautery for tonsillectomy, which causes less blood loss. According to our findings, in early tonsillectomy tissues were friable and plane for dissecting out tonsil was difficult to find because of continuous oozing of blood and friable tissues. It took almost double the time to remove the infected tonsil as compared to the opposite normal tonsil and perioperative blood loss was also more than that in delayed tonsillectomy. In delayed tonsillectomy, dissection is also difficult as compared to normal tonsil. Ghauri SM et al. and Javed $\mathrm{M}$ et al. ${ }^{17,18}$ had shown more perioperative blood loss in late tonsillectomy as compared to early tonsillectomy but their results were not significant. There was no case of primary hemorrhage after tonsillectomies, however there were 7 cases of secondary mild postop hemorrhage in group A versus 3 in group B $(p=0.289)$ in our study. All these cases settled on conservative measures, i.e. admission, intravenous antibiotics, fluids and bed rest.

The benefit of performing early tonsillectomy is shortened hospital stay ${ }^{13}$ as the patient gets incision and drainage in same admission while delayed tonsillectomy requires two separate admissions. Post-op bed rest is advised after both procedures.

\section{Limitation of Study}

The surgeries for peritonsillar abscess were performed by two different ENT specialists. The results could be different owing to different surgical skills of the ENT specialists.

\section{Conclusion}

The study concluded that interval tonsillectomy is a better option as compared to early tonsillectomy (less perioperative blood loss, less operative time, easy dissection and almost similar postop pain and similar risk of post tonsillectomy hemorrhage).

\section{REFERENCE}

1. Ehlers Klug $\mathrm{T}$, Rusan $\mathrm{M}$, Fuursted $\mathrm{K}$, Oversen $\mathrm{T}$. Fusobacterium Necrophorum: most prevalent pathogen in peritonsillar abscess in Denmark. Clin Infect Dis. 2009; 49: 1467-72.

2. Johnson RF, Stewart MG, Wright CC. An evidence based review of the treatment of peritonsillar abscess. Otolaryngol Head Neck surg. 2003; 128: 332-43.

3. LeBlond RF, DeGowin RL, Brown DD. DeGrowin's diagnostic examination. 8th Ed. New York: McGraw-Hill. 2004; 303.

4. Brojerdian S, Bisschop P. Clinical advantage of abscess tonsillectomy in peritonsillar abscess. Acta otolaryngol Belg. 2000; 54: 459-64.

5. Lee MS, Montague ML, Hussain SS. The admission of patients with peri-tonsillar abscess to a general ENT ward. Clin Otolaryngology Allied Sci. 2003; 28: 48-50.

6. Brook I, Frazier EH, Thompson DH. Aerobic and anaerobic microbiology of peritonsillar abscess. Laryngoscope. 1991; 101: 289-92.

7. Galioto NJ. Peritonsillar Abscess: Am Fam Physician. 2008; 77: 199-202.

8. Lehnerdt G, Senska K, Jahnke K, Fischer M. Posttonsillectomy haemorrhage: a retrospective comparison of abscess and elective tonsillectomy. Acta Otolaryngol. 2005: 125: 1312-7.

9. Steyer TE. Peritonsillar abscess: diagnosis and treatment [Published correction appears in Am Fam Physician. 2002; 65: 93-6.

10. Khayr W, Taepke J. Management of peritonsillar abscess: needle aspiration versus incision and drainage versus tonsillectomy. Am J Ther. 2005; 12: 344-50.

11. Klug TE. Peritonsillar abscess: Clinical aspects of microbiology, risk factors and association with parapharyngeal abscess. Dan Med J. 2017; 64: B5333. 
12. Johnson RF, Stewaet MG. The contemporary approach to diagnosis and management of peritonsilla abscess. Curr Opin Otolaryngol Head Neck Surg. 2005; 13: 157-60.

13. Ahmad MM, Iqbal J, Amjad M. Early interval tonsillectomy as compared to delayed interval tonsillectomy reduces the risks of complications - A comparative study. Pak J Med Health sci. 2017; 11: 721-4.

14. Raut VV, Yung MW. Peritonsillar abscess; The rationale for interval tonsillectomy. Ear Nose Throat J. 2000; 79: 206-9.

15. Prasad KC, Prasad SC. Assessment of operative bloodloss and the factors affecting it in tonsillectomy and adenotonsillectomy. Indian J Otolaryngol Head Neck Surg. 2011; 63:343-8.
16. Negm $\mathrm{H}$, Atef A, Lesheen $\mathrm{H}$, Kamel AA, Azook K, Elhoussainy $O$. Factors affecting secondary post-tonsillectomy hemorrhage: a case control study. Egypt J Otolaryngol. 2017; 33:50-5.

17. Javed M, Wahid F, Khan N, Khan Q, Shahabi IK. Interval tonsillectomies; comparison of per and post operative complications in patients undergoing early and delayed tonsillectomy after peritonsillar abscess. Professional Med J. 2014; 21:1043-7.

18. Ghauri SM, Rohail A, Nasrulla M. Immmediate and delayed tonsillectomy as a part of treatment of quinsy. Pak J Med Health Sci. 2017; 11: 62-25. 